\title{
A study on the effect of social capital on job satisfaction and citizenship behaviour
}

\author{
Roghiyeh Khodaei $^{\mathrm{a}^{*}}$, Hassan Khodaei Valehzaghard ${ }^{\mathrm{b}}$ and Hamidreza Anvar ${ }^{\mathrm{c}}$
}

\begin{abstract}
${ }^{a}$ Department of social welfare planning, Social Science Faculty, Tehran University, Tehran, Iran
${ }^{b} P$ h.D, student of industrial management, Allameh Tabataba'i University, Tehran, Iran

${ }^{c}$ Department of Industrial Management, Qazvin Branch, Qazvin, Islamic Azad University (IAU), Iran

CHRON I CLE ABSTRACT

Article history:

Received May 12, 2013

Received in revised format

25 June 2013

Accepted 27 June 2013

Available online

June 292013

Keywords:

Social capital

Citizenship behavior

Job satisfaction

Social capital is one of the most important assets of any organization and it plays essential role in reaching organizational objectives. In this paper, we present an empirical study to study the effect of social capital on job satisfaction and citizenship behavior. The proposed study is performed among 240 employees who work for Allameh Tabataba'i University in Iran. The study designs a questionnaire in Likert scale and distributes it among selected employees and, using structural equation modeling, investigates the role of social capital on job satisfaction as well as citizenship behavior. The preliminary results of our survey indicate that social capital positively influences on both mentioned variables.
\end{abstract}

\section{Introduction}

Social capital is considered one of the most essential factors for the success of organizations and there are literally various studies to measure the impact of social capital on other organizational objectives such as job satisfaction, better cooperation, etc. During the past two decades, there have been various studies on these issues. Williams and Anderson (1991), for instance, investigated the relationship of job satisfaction and organizational commitment as predictors of organizational citizenship and in-role behaviors. Podsakoff et al. (1997) studied the effect of organizational citizenship behavior and the quantity and quality of work group performance. Chen and Chiu (2009) investigated the mediating role of job involvement in the relationship between job characteristics and organizational citizenship behavior. Nazari (2013) performed a study on the role of social capital on one of newly established private banks in Iran called Ghavamin. The proposed study designed a questionnaire for measuring the level of social capital in terms of cognitive capital, relational capital and structural capital and

*Corresponding author. Tel: +989123443139

E-mail addresses: sara.khoda@ymail.com (R. khodaei) 
distributed it among 30 out 67 employees of one their branches in city of Qom, Iran. The results indicated that none of social components had been in satisfactory level terms of social capital.

Saadi, and Pahlavani (2013) studied the effect of social capital on knowledge creation in Petrochemical Industry. According to Veismoradi et al. (2012), one of the challenges in contemporary zone of management and organizational behavior is to build and strengthen social capital. Social capital arises from individuals trying to assist people to build trust, relationships and cooperation. Without social capital, employees are unable to share information and knowledge. Veismoradi et al. (2012) studied the relationship of social capital and the learning organizational in one of Iranian organizations called Jihad Agriculture Organization of Kermanshah. They reported that social capital had a meaningful relationship with learning organizational.

Alinajafi et al. (2012) investigated the relationship between social capital and employee participation in Gurgan Medical Science University. The results indicated that there was an indirect relationship between employee participation networks and employee participation, an indirect relationship between trust and closeness with employee participation and there was an indirect relationship between employee closeness and employee participation. The investigation also indicated that there was a relationship between trust grade and employee participation. In other words, as trust grade increases there was an increase in employee participation. Another observation was that there was an indirect relationship between employee communication networks and participation. In addition, there was a direct relationship between communication network and closeness as well as trust, which means that as communicational network increases, trust and closeness grades in organization increase too.

Iravani and Razi (2011) reported a positive and meaningful relation between social capital and social solidarity. In addition, there was a negative and meaningful relationship between social opposition and conflict with organizations while there were some reverse relationships among networks of social relationships instead of level of internal group relationships. Esfahani et al. (2013) investigated the relationship between job involvement and organizational commitment among lower-level employees in Iranian automaker industry. In this study, job involvement was an independent variable, organizational commitment was dependent variable, and the analysis is performed using 100 randomly selected data through a questionnaire, which consists of four-parts. The study reported that job involvement was strongly associated with organizational commitment.

Shahabi et al. (2012) tried to find organizational intelligence dismounting barriers prioritization and detected important barriers and prioritized them using analytical hierarchy process. Based on the results of this paper, structural barriers were considered as the most important issue followed by legal barriers, cultural and executive barriers. The results of their survey indicated that lack of organizational knowledge management relation with daily activities, project complexity, lack of the knowledge exchanging and sharing in the organization, lack of suitable business context and absence of a documented program for the organizational intelligence dismounting had been among the most important barriers.

\section{The proposed study}

In this study, we present an empirical study to study the effect of social capital on job satisfaction and citizenship behavior. The proposed study is performed among 240 employees who work for Allameh Tabataba'i University in Iran. The study designs a questionnaire in Likert scale and distributes it among selected employees and, using structural equation modeling, investigates the role of social capital on job satisfaction as well as citizenship behavior. Fig. 1 shows details of our proposed model. 
Fig. 1. The proposed study

Based on the structure of the proposed study given in Fig. 1, the following hypotheses are derived.

1. There is a relationship between social capital and citizenship behavior.

2. There is a relationship between social capital and job satisfaction.

3. There is a relationship between job satisfaction and citizenship behavior.

Cronbach alpha for social capital, job satisfaction and citizenship behavior are 0.955, 0.89 and 0.848, respectively and these are well above the minimum acceptable level of 0.70 . In our study, there were 149 female and 91 participants were male. Fig. 2 demonstrates other relative personal information of the surveyed participants.

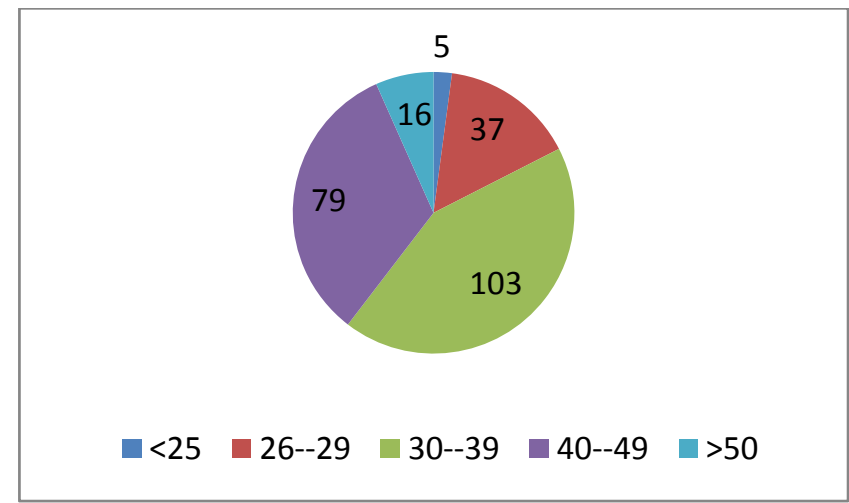

Age

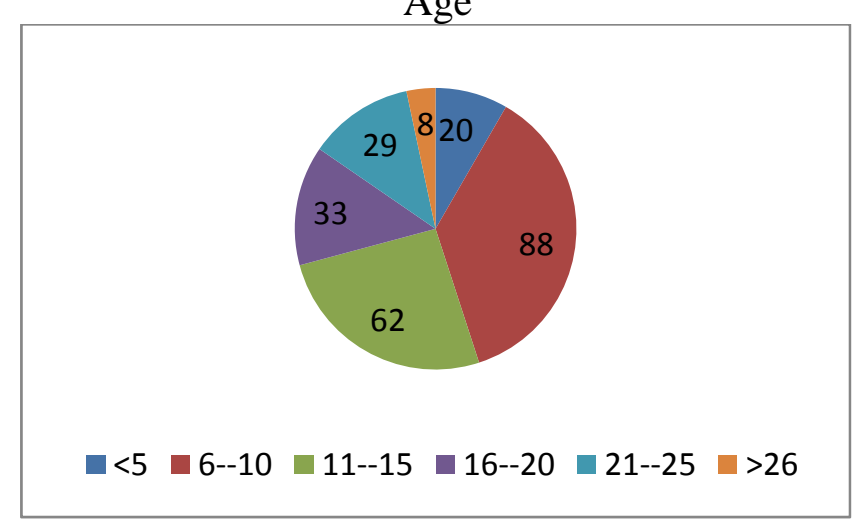

Years of experience

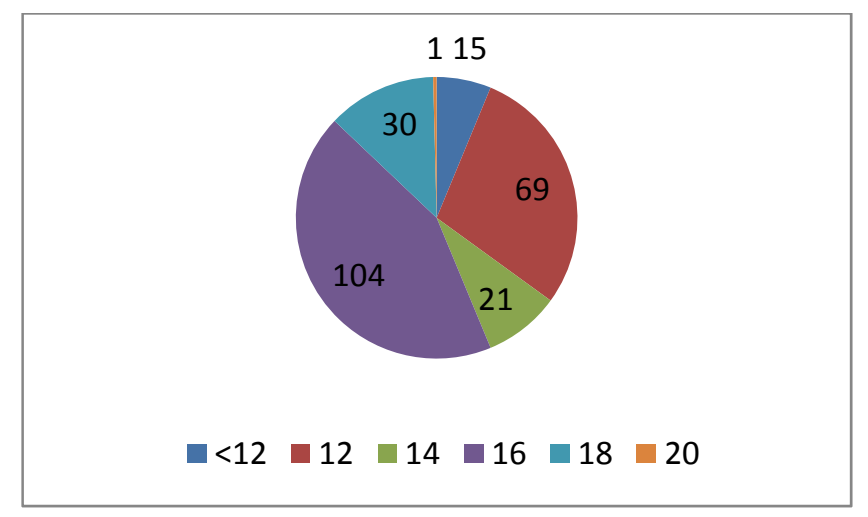

Years of educational background

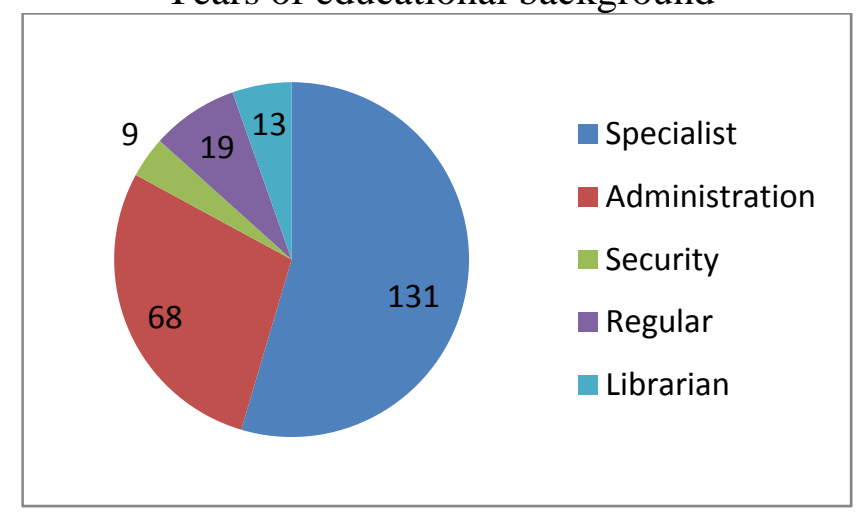

Type of job

Fig. 1. Personal characteristics of the participants

As we can observe from the results of Fig. 1, most participants had at least five years of job experiences, there were enrolled in high skilled jobs, there were mostly middle age workers and maintained university educational backgrounds.

\section{The results}

In this section, we present details of the implementation of structural equation modeling for testing three hypotheses of the survey. Fig. 2 shows details of our results. 


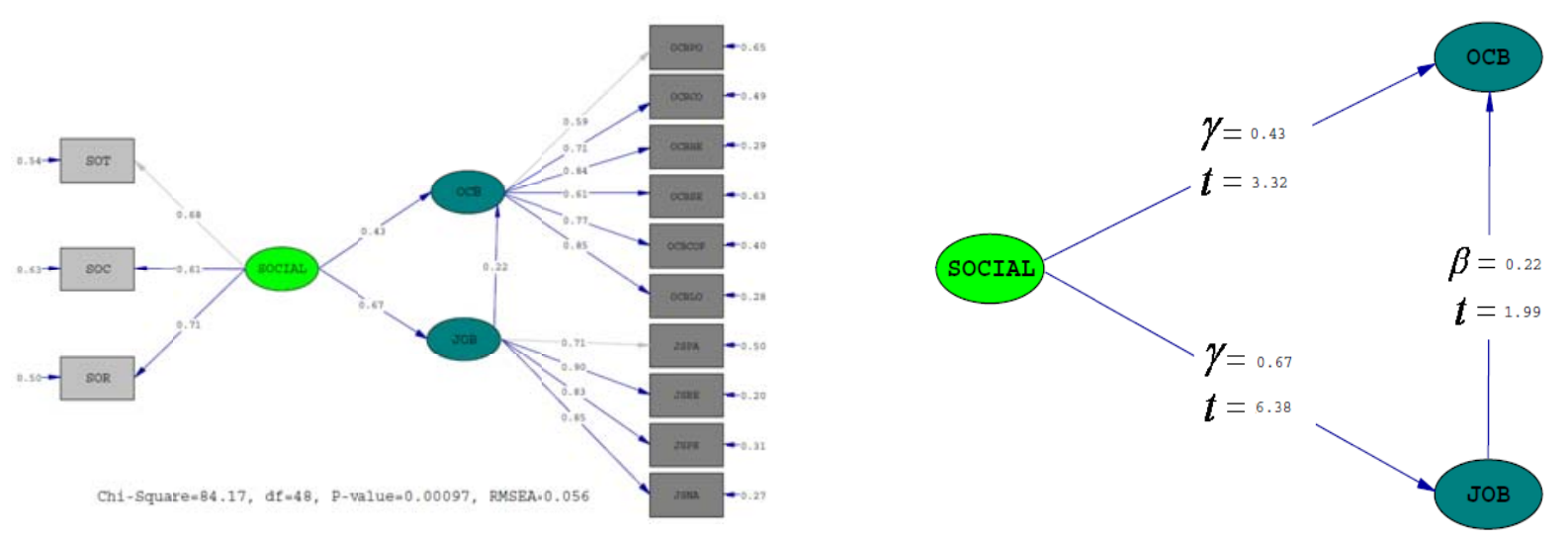

Fig. 2. The results of structural equation modeling

There are different criteria to validate the proposed study such as root mean square error of spproximation (RMSEA), normed fit index (NFI), non-normed fit index (NNFI), goodness of fit index (GFI) and root mean square residual (RMSE). These indicators must be within acceptable limits to validate the overall survey. In our survey, RMSEA=0.056, NFI=0.98, NNFI=0.98, GFI= 0.95 and RMSE $=0.023$. These are within acceptable limits and we can confirm the overall results.

\subsection{The first hypothesis: The relationship between social capital and citizenship behavior}

The first hypothesis of this survey investigates the relationship between social capital and citizenship behavior, which is stated as follows,

$$
\left\{\begin{array}{l}
H_{0}: \gamma_{S O, O C B}=0 \\
H_{1}: \gamma_{S O, O C B} \neq 0
\end{array}\right.
$$

In our survey, $\gamma=0.43$ and t-student $=3.32$ and the result is meaningful when the level of significance is five percent. The gamma value indicates the effect of social capital on citizenship behavior. We have performed a linear regression analysis and Table 1 summarizes the results of our survey.

\section{Table 1}

The results of linear regression analysis

\begin{tabular}{cccccc}
\hline \multirow{2}{*}{ Variable } & \multicolumn{2}{c}{$\begin{array}{c}\text { Non-standard value } \\
\text { B }\end{array}$} & Standard error & $\begin{array}{c}\text { Standard value } \\
\text { Beta }\end{array}$ & t-student \\
\hline Intercept & 0.152 & 0.021 & & 7.421 & 0 \\
Social capital & 1.829 & 0.165 & 0.582 & 11.049 & 0 \\
Std. Error of the Estimate $=.318$ & $\mathrm{R}^{2}=.339$ & $\mathrm{R}=.582$ & $\mathrm{~F}=122.077, \mathrm{P}=.000$ \\
\hline
\end{tabular}

The results of regression analysis yield meaningful t-student values for both intercept and independent variable when the level of significance is one percent. In addition, F-value is statistically significance, which means the relationship is linear. Therefore, the first hypothesis of this survey is confirmed and we can conclude that there is a positive and meaningful relationship between social capital and citizenship behavior.

\subsection{The second hypothesis: the relationship between social capital and job satisfaction}

The second hypothesis of this survey considers whether there is a relationship between social capital and job satisfaction or not. This hypothesis itself consists of three sub-hypotheses including the relationship between trust and job satisfaction, the relationship between social participation and job satisfaction and finally, the relationship between social network and job satisfaction. The Pearson correlation for trust, social participation and social network with job satisfaction were calculated as 
$0.35,0.313$ and 0.516 , respectively and they are all meaningful when the level of significance is five percent. Therefore, the second hypothesis of the survey has been confirmed.

\subsection{The third hypothesis: The relationship between job satisfaction and citizenship behavior}

The last hypothesis of this survey investigates the relationship between citizenship behavior and job satisfaction, which is stated as follows,

$\left\{\begin{array}{l}H_{0}: \beta_{J S, O C B}=0 \\ H_{1}: \beta_{J S, O C B} \neq 0\end{array}\right.$

In our survey, $\gamma=0.22$ and t-student $=1.99$ and the result is meaningful when the level of significance is five percent. The gamma value indicates the effect of job satisfaction on citizenship behavior. We have performed a linear regression analysis and Table 2 summarizes the results of our survey.

\section{Table 2}

The results of regression analysis between job satisfaction and citizenship behavior

\begin{tabular}{|c|c|c|c|c|c|c|}
\hline \multirow{2}{*}{ Variable } & \multicolumn{2}{|c|}{ Non-standard coefficients } & \multirow{2}{*}{$\begin{array}{c}\text { Standard } \\
\text { Beta }\end{array}$} & \multirow{2}{*}{ t-student } & \multirow{2}{*}{\multicolumn{2}{|c|}{ Error }} \\
\hline & $\mathrm{B}$ & Standard error & & & & \\
\hline Intercept & 0.112 & 0.022 & & 5.083 & & 0 \\
\hline Job satisfaction & 0.273 & 0.03 & 0.512 & 9.188 & & 0 \\
\hline \multicolumn{2}{|c|}{ Std. Error of the Estimate $=.336$} & $\mathrm{R}^{2}=.262$ & $\mathrm{R}=.512$ & $\mathrm{~F}=84$ & & \\
\hline
\end{tabular}

The results of regression analysis yield meaningful t-student values for both intercept and independent variable when the level of significance is one percent. In addition, F-value is statistically significance, which means the relationship is linear. Therefore, the first hypothesis of this survey is confirmed and we can conclude that there is a positive and meaningful relationship between job satisfaction and citizenship behavior. Therefore, we can confirm the third hypothesis of this survey and state that job satisfaction definitely influences citizenship behavior, positively.

In this survey, we have also investigated the effect of payment, human relationship, job promotion and job identity on citizenship behavior and the Pearson correlation ratio for these four components were calculated as $0.361,0.474,0.462$ and 0.517 with P-value $=0.000$. Therefore, we can observe that there are positive effects from these four components towards citizenship behavior.

\section{Conclusion}

In this paper, we have presented an empirical study to find the effect of social capital on job satisfaction and citizenship behavior. The study investigated whether there was any meaningful relationship between social capital and citizenship behavior, any relationship between social capital and job satisfaction and finally whether there was any meaningful relationship between job satisfaction and citizenship behavior. Using structural equation modeling, the study has confirmed all three hypotheses of the survey. In addition, the study considered the relationship between trust and job satisfaction, the relationship between social participation and job satisfaction and finally, the relationship between social network and job satisfaction. The Pearson correlation for trust, social participation and social network with job satisfaction were calculated as $0.35,0.313$ and 0.516 , respectively and they are all meaningful when the level of significance is five percent. Finally, we have investigated the effect of payment, human relationship, job promotion and job identity on citizenship behavior and the Pearson correlation ratio for these four components were calculated as $0.361,0.474,0.462$ and 0.517 with P-value $=0.000$. Therefore, we can observe that there are positive effects from these four components towards citizenship behavior. 


\section{References}

Alinajafi, Z., Askarinejad, M., Veiseh, S \& Kamari, F. (2012). The relationship between social capital and employee participation in Gorgan medical science university. Management Science Letters, 2(3), 819-826.

Chen, C. C., \& Chiu, S. F. (2009). The mediating role of job involvement in the relationship between job characteristics and organizational citizenship behavior. The Journal of social psychology, 149(4), 474-494.

Esfahani, M., Emami, M \& Tajnesaei, H. (2013). The investigation of the relation between job involvement and organizational commitment. Management Science Letters, 3(2), 511-518.

Iravani, M \& Razi, Z. (2011). An empirical study to investigate the effects of social capital on social contribution. Management Science Letters, 1(4), 607-612.

Nazari, M. (2013). A study on social capital in banking industry: A case study of Ghavamin bank. Management Science Letters, 3(4), 1187-1190.

Podsakoff, P. M., Ahearne, M., \& MacKenzie, S. (1997). Organizational citizenship behavior and the quantity and quality of work group performance. Journal of applied psychology, 82(2), 262-270.

Saadi, M \& Pahlavani, N. (2013). The effect of social capital on knowledge creation in Petrochemical Industry. Management Science Letters, 3(3), 879-884.

Shahabi, A., Faez, A \& Fazli, D. (2012). Organizational intelligence dismounting barriers prioritization: A real-world case study. Management Science Letters, 2(8), 3013-3022.

Veismoradi, A., Akbari, P \& Rostami, R. (2012). A study on the effect of social capital on learning organization: A case study of Jihad Agriculture Organization of Kermanshah, Iran. Management Science Letters, 2(8), 2909-2916.

Williams, L. J., \& Anderson, S. E. (1991). Job satisfaction and organizational commitment as predictors of organizational citizenship and in-role behaviors. Journal of management, 17(3), 601617. 